\title{
Host-pathogen interactions and immune evasion strategies in Francisella tularensis pathogenicity
}

\author{
This article was published in the following Dove Press journal: \\ Infection and Drug Resistance \\ 18 September 2014 \\ Number of times this article has been viewed
}

\author{
Don J Steiner \\ Yoichi Furuya \\ Dennis W Metzger \\ Center for Immunology and \\ Microbial Disease, Albany Medical \\ College, Albany, NY, USA
}

Correspondence: Dennis W Metzger

Center for Immunology and Microbial

Disease, MC-15I, Albany Medical

College, 47 New Scotland Avenue,

Albany, NY 12208, USA

$\mathrm{Tel}+\mathrm{I} 5 \mathrm{I} 82626750$

Fax +I 5182626053

Email metzged@mail.amc.edu

\begin{abstract}
Francisella tularensis is an intracellular Gram-negative bacterium that causes life-threatening tularemia. Although the prevalence of natural infection is low, F. tularensis remains a tier I priority pathogen due to its extreme virulence and ease of aerosol dissemination. F. tularensis can infect a host through multiple routes, including the intradermal and respiratory routes. Respiratory infection can result from a very small inoculum (ten organisms or fewer) and is the most lethal form of infection. Following infection, F. tularensis employs strategies for immune evasion that delay the immune response, permitting systemic distribution and induction of sepsis. In this review we summarize the current knowledge of $F$. tularensis in an immunological context, with emphasis on the host response and bacterial evasion of that response.
\end{abstract}

Keywords: LVS, Schu S4, tularemia, host immunity, Francisella tularensis

\section{Introduction}

The bacterium Francisella tularensis is the causative agent of the disease tularemia. Originally discovered in ground squirrels in Tulare County, CA, USA, F. tularensis has previously been termed Bacterium tularense and Pasteurella tularensis. ${ }^{1-3}$ The first known infection of a human with $F$. tularensis was identified in $1913 .{ }^{2}$ The bacterium has a coccobacillus shape, stains Gram-negative, and is nonmotile., ${ }^{4,5}$

F. tularensis exists as multiple subspecies, including the "type A" subspecies F. tularensis tularensis and the "type B" subspecies F. tularensis holarctica and F. tularensis mediasiatica. Additionally, there exists a related species, Francisella novicida. ${ }^{6-8}$ Subspecies $F$. tularensis tularensis, holarctica, and mediasiatica can all cause infection in humans, although only subspecies $F$. tularensis tularensis is appreciably lethal. By contrast, F. novicida has been reported to cause infection only in immunocompromised individuals. ${ }^{7}$

Humans can contract infection with $F$. tularensis through several routes, including arthropod bites, contact with infected animals or animal carcasses, ingestion of contaminated materials, or inhalation. ${ }^{6,9}$ Infection typically produces a febrile illness, although specific pathology and mortality rates are highly dependent upon the route of infection. ${ }^{1,2,6,10}$ The most common presentation is glandular or ulceroglandular tularemia, in which infection occurs through the skin and causes localized inflammation and infection of local lymph nodes. ${ }^{6}$ Ulcers produced by ulceroglandular tularemia are persistent, but the infection is rarely lethal and can often resolve without treatment. ${ }^{6}$ F. tularensis can also cause typhoidal tularemia, which is characterized by systemic infection without lymphadenopathy or development of ulcers. ${ }^{6}$ Typhoidal tularemia is more serious, with a mortality rate potentially as high as $60 \% .{ }^{6}$ Less commonly, 
infection can present as oropharyngeal or gastrointestinal tularemia resulting from ingestion of contaminated materials, or as oculoglandular tularemia as a result of infection of the conjunctiva of the eyes. ${ }^{6}$ The most serious form of Francisella infection, pneumonic tularemia, is typically caused by inhalation of bacterial aerosols or airborne suspensions of infectious material. Type A F. tularensis is extraordinarily infectious and highly lethal when infection occurs through the respiratory route, with a case fatality rate in excess of $60 \%$ and a minimum infectious dose of fewer than 10 colony-forming units (CFU). ${ }^{10}$

The extreme respiratory infectivity of type A F. tularensis and its high survivability as an aerosol, combined with the high lethality of the pneumonic form of infection, have made the organism an attractive candidate for weaponization, and several governments produced large quantities of F. tularensis for that purpose during the 20th century. ${ }^{8,11-14}$ Today, F. tularensis remains a potential agent of biological terrorism. ${ }^{14}$ To date, there is no licensed vaccine against F. tularensis. An attenuated strain of type B F. tularensis, the live vaccine strain (LVS), was developed in the mid-20th century by serial passage of $F$. tularensis holarctica through mice. ${ }^{15,16}$ LVS is attenuated in humans but retains virulence in mice. Salomonsson et $\mathrm{al}^{17}$ found that complementation of LVS with the genes pilA and FTT0918 restored virulence to the level of virulent type B strains in subcutaneous infection. However, the mechanisms responsible for attenuation of LVS, particularly in models of respiratory infection, remain incompletely understood, leading to fears that LVS may revert to virulence or may cause disease in immunocompromised individuals.

\section{Virulence determinants}

Several virulence determinants have been proposed for F. tularensis, many of which are expressed as components of the Francisella pathogenicity island. ${ }^{18}$ These bacterial products, as well as others, augment virulence through several mechanisms, including suppression of the host immune response and facilitation of phagosomal escape and intracellular survival.

The Francisella pathogenicity island was first described in 2004. ${ }^{19}$ It contains 17 open reading frames of varying size, several of which have been identified as essential for pathogenesis. ${ }^{19}$ Intriguingly, the Francisella pathogenicity island is characterized by a lower percentage of guanine and cytosine nucleotides compared with the rest of the Francisella genome, which itself has a fairly low guanine and cytosine content. ${ }^{18,19}$ In the study that identified the Francisella pathogenicity island, the $p d p A$ gene was identified as being essential for virulence, but its function and the functions of the other $p d p$ genes are not known. ${ }^{19,20}$ The $p d p D$ gene was found to be present in F. novicida and in type A subspecies of F. tularensis but not in type B subspecies, and it has been implicated in intramacrophage survival. ${ }^{18,19}$ Several genes within the Francisella pathogenicity island, including vgrG, $\operatorname{dot} U$, and many of the $I g l$ genes, share sequence homology as well as biochemical and structural characteristics with type VI secretion genes of other bacteria. ${ }^{21,22}$ It is therefore not surprising that the products of $v g r G$ and $I g l I$ have been found to be secreted by the bacterium during intracellular infection. ${ }^{23}$ Several Francisella pathogenicity island proteins, including the IglC protein, have been shown to inhibit phagosome maturation. ${ }^{24,25}$ These proteins also appear to be involved in escape from the phagosome and intracellular survival. IglC and clpB have also been implicated in evasion of immunity, as F. novicida mutants with defects in these genes fail to induce secretion of immunosuppressive prostaglandin $\mathrm{E}_{2}\left(\mathrm{PGE}_{2}\right) \cdot{ }^{26}$ It is worth noting that most of the proteins secreted by the Francisella type VI secretion system, with the exception of vgrG, are unique to the Francisella genus. ${ }^{27}$

Control of reactive oxygen species (ROS) and nitrogen species is also an essential component of Francisella virulence. The enzyme KatG possesses both catalase and peroxidase properties, allowing it to detoxify hydrogen peroxide as well as reactive nitrogen species. ${ }^{28,29} \mathrm{KatG}$ plays a significant role in the virulence of $F$. tularensis LVS, as mutants lacking a functional katG gene failed to kill mice after intraperitoneal inoculation. ${ }^{29}$ In contrast, $k a t G$ mutants of Schu S4 were sensitive to hydrogen peroxide and reactive nitrogen species in vitro but retained lethality in mice, indicating that KatG is a sufficient but not necessary virulence factor. ${ }^{29}$ Similarly, the superoxide dismutases SodB and SodC are essential for bacterial resistance to superoxide radicals, as F. tularensis LVS mutants of either enzyme are highly attenuated in mice challenged intranasally. ${ }^{30,31}$

\section{Host-pathogen interactions Bacterial survival and replication}

F. tularensis has long been considered to be an intracellular pathogen. The first evidence that $F$. tularensis could replicate intracellularly came from studies of infected chick embryos and, later, HeLa cells. ${ }^{32,33}$ Notably, these early investigations showed that bacteria were present in the cytoplasm of infected cells.

Later work demonstrated that $F$. tularensis is also capable of replicating within macrophages. In 1995, Fortier et $\mathrm{al}^{34}$ 
showed that $F$. tularensis LVS grew to high concentrations in the presence of peritoneal macrophages but not in the presence of lysed macrophages or in macrophage-conditioned media. F. tularensis is taken up by macrophages through a unique form of phagocytosis called "looping phagocytosis", in which extensions of the cell membrane engulf a large volume of space surrounding the bacterium in an actindependent manner. ${ }^{35,36}$ The large space within the loop does not result from the presence of a bacterial capsule, as the volume of the vacuole is reduced rapidly after phagocytosis. ${ }^{36}$ Entry into the cell can involve a variety of surface receptors, including mannose receptors, Fc receptors, and complement receptors..$^{35,37-40}$ Both virulent and attenuated strains of F. tularensis survive phagocytosis by preventing acidification of the phagosome and arresting its maturation, and the organism ultimately escapes into the cytoplasm. ${ }^{41-43}$ This process is summarized in Figure 1. There is evidence that following escape of $F$. tularensis LVS into the cytoplasm, a proportion of cytoplasmic bacteria re-enters the endocytic pathway through autophagy. ${ }^{44}$ It is not certain whether this process is an adaptive strategy by the bacterium or a part of the cellular defense against infection; however, evidence suggests that autophagy provides intracellular bacteria with nutrients required for replication. ${ }^{45}$ The replication process ends in the destruction of the host cell. Lai et $\mathrm{a}^{46}$ have shown that infection of the macrophage-like J774 cell line with LVS

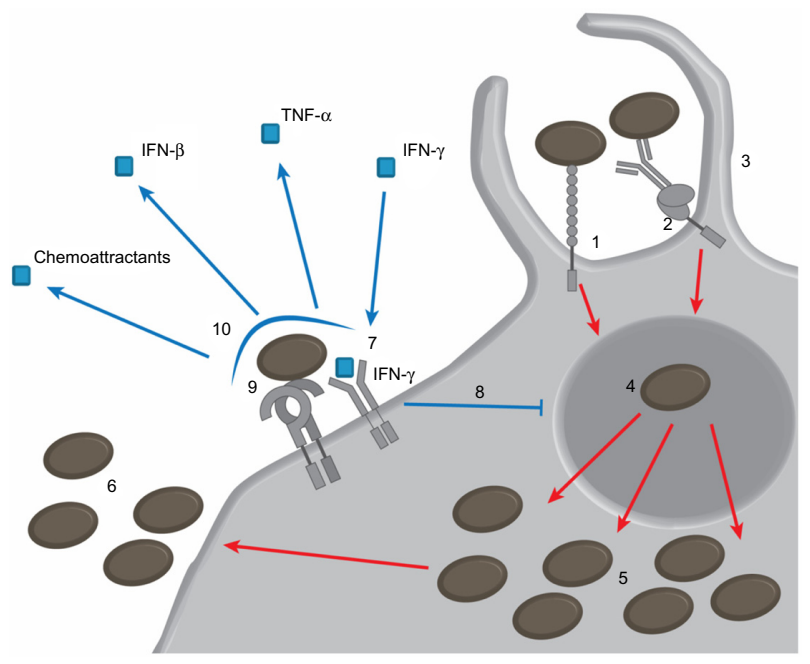

Figure I Francisella tularensis (brown) binds to the cell surface using receptors such as the mannose receptor (I) or, in the case of opsonized bacteria, Fc receptors (2) or complement receptors. Bacteria enter the cell through looping phagocytosis (3) but survive by preventing maturation of the phagosome (4). F. tularensis escapes the phagosome to replicate in the cytoplasm (5), ultimately inducing apoptosis and escaping the cell (6). When macrophages are simulated by exposure to IFN- $\gamma(7)$, they can restrict intracellular replication (8). Stimulation by IFN- $\gamma$ and stimulation of Toll-like receptor 2 (9) can also lead to secretion of inflammatory cytokines and chemoattractants (10).

Abbreviations: IFN, interferon; TNF, tumor necrosis factor. results in apoptosis. This apoptosis is not a self-sacrificing defense mechanism on the part of the cell, as apoptosis was not observed to reduce bacterial numbers.

F. tularensis may also be able to use nonmacrophage cells as hosts. LVS has been observed to replicate within alveolar type II (ATII) epithelial cells in vitro, and experiments using green fluorescent protein-expressing $F$. tularensis of both type A and type B strains have detected labeled bacteria within neutrophils after intranasal infection. ${ }^{47,48}$ Experiments employing LVS and Schu S4 $\Delta p y r F$ mutants, which fail to replicate within primary macrophages, showed that such mutants were fully virulent in mice infected intranasally, suggesting that $F$. tularensis is not dependent upon replication within macrophages for survival and virulence. ${ }^{49}$ Despite the proclivity of $F$. tularensis for intracellular replication, the majority of bloodborne bacteria of both type A and type B strains are extracellular. ${ }^{50,51}$

Iron is a key requirement for intracellular growth of F. tularensis. ${ }^{34,52,53}$ Investigators have found that iron concentrations in growth media can affect expression of the Francisella pathogenicity island genes and can induce the organism to adopt a "host-adapted" phenotype. ${ }^{18,54}$ There is evidence that $F$. tularensis actively modulates expression of transferrin receptors in order to promote delivery of iron to the phagosome during the early stages of intracellular growth. ${ }^{55}$ However, iron uptake may paradoxically render bacteria more susceptible to intracellular killing by ROS. ${ }^{56}$ The highly virulent type A strain Schu S4 has been shown to have a lower iron content than the attenuated type B strain LVS, which may be a factor in the latter's reduced virulence. $^{56}$

\section{Pathogenesis}

The earliest descriptions of tularemia included animals as varied as rodents, lagomorphs, and monkeys. These studies indicated that infection produced a febrile illness and generated foci of infection and necrotic inflammation in the lymph nodes as well as in dispersed organ sites. ${ }^{1,57}$ Morphological changes to the liver and spleen, particularly splenomegaly, have also been observed. ${ }^{57,58}$ Pneumonia is a frequent occurrence, even when the initial infection occurs through a route other than the respiratory route. ${ }^{10,59,60}$ Following intravenous infection with F. tularensis LVS, infectious foci were detected in liver tissue after 16 hours, accompanied by infiltration of both neutrophils and monocytes. ${ }^{61}$ Systemic dissemination also occurs following respiratory infection. Following aerosol infection with $F$. tularensis LVS, bacteria can be isolated from livers and spleens as early as 48 hours later. ${ }^{62}$ In humans, 
infection is known to produce fever, persistent malaise, and ulcerous lesions or buboes. , $10,59,60^{2}$

A major factor in F. tularensis pathogenicity is its capacity for intracellular replication. It has long been recognized that $F$. tularensis can replicate within host cells, ${ }^{32,33}$ and particularly macrophages. ${ }^{46,63,64}$ This intracellular replication strategy contributes to pathogenesis as infected cells either apoptose or become lysed by uninfected immune cells. ${ }^{46,61}$ Intracellular replication may also play a role in dissemination of the infection to distant sites. In 2008, Bar-Haim et al ${ }^{65}$ showed that following intranasal F. tularensis LVS infection, dendritic cells trafficked to the mediastinal lymph nodes, which quickly became severely infected.

Death in F. tularensis infection appears to result from widespread sepsis and inflammation rather than bacterial pneumonia, even when infection occurs through the respiratory route. ${ }^{6-69}$ In a study of pneumonic F. tularensis LVS infection, high levels of inflammatory cytokines and chemokines in the lungs and spleen, including interleukin (IL)-6, macrophage inflammatory protein 2, and chemokine ligand 2, were correlated with mortality. ${ }^{58}$ Investigations involving respiratory infection with $F$. tularensis Schu S4 and F. novicida showed that lethal infection was associated with hypercytokinemia and biochemical markers for sepsis. ${ }^{66,69}$ This sepsis may result from the fact that in F. tularensis infection, upregulation of cytokine production and inflammatory cell recruitment is delayed, ${ }^{66}$ and the high degree of apoptotic cell debris associated with $F$. tularensis infection leads to alternative activation of macrophages, impeding bacterial clearance. ${ }^{70}$ In lung infection, excessive levels of neutrophil recruitment may also contribute to pathology. Although neutrophil recruitment is delayed in Francisella infection, ${ }^{66}$ high levels of neutrophil recruitment are associated with increased lung histopathology and, somewhat paradoxically, high bacterial burden. ${ }^{71}$ These findings may be explained in part by observations that human neutrophils infected with F. tularensis LVS or Schu S4 exhibit a delay in time to apoptosis, preventing resolution of inflammation. ${ }^{72}$

\section{Innate immunity}

The type 1-associated immune pathway is known to be an important factor in protection from $F$. tularensis infection. After cutaneous infection with $F$. tularensis LVS, immunized mice produced large quantities of IL-12 within 24 hours of infection. ${ }^{73}$ Another study found that IL-12 p40-knockout mice failed to clear LVS administered intraperitoneally, even after immunization by sublethal intradermal infection. ${ }^{74}$ These mice also had significantly lower levels of serum interferon
(IFN)- $\gamma$, suggesting a connection between secretion of IL-12 and the IFN- $\gamma$ response. The p40 subunit of IL-12 was also shown to induce migration of dendritic cells from the lungs to the draining lymph nodes after LVS infection. ${ }^{75}$

After intradermal infection with LVS, IFN- $\gamma$ messenger ribonucleic acid expression can be detected within 48 hours in naïve mice and within 24 hours in immunized mice. ${ }^{73}$ In F. tularensis infection, both natural killer (NK) cells and T-cells are important producers of IFN- $\gamma$, although NK cells are the dominant source at early time points. ${ }^{76,77}$ Following intranasal F. tularensis LVS infection, NK cells are among the first cells recruited to the lungs, and can be observed to secrete IFN- $\gamma$ within 72 hours of infection. ${ }^{76,78} \mathrm{NK}$ cells primed with bacterial deoxyribonucleic acid can reduce replication of $F$. tularensis LVS in macrophages, even in the absence of T- or B-cells, and this effect is dependent upon IFN- $\gamma$ and TNF- $\alpha{ }^{79}$ IFN- $\gamma$ is essential to host survival following pneumonic infection, as IFN- $\gamma$ knockout mice challenged by the respiratory route exhibited greater rates of mortality and higher lung bacterial burden than wild-type (WT) mice. ${ }^{80,81}$ Although exogenous treatment with IL-12 was shown to be protective against intranasal infection, this protection was not evident in IFN- $\gamma$ knockout mice, indicating that the protective effect of IL-12 is dependent upon IFN- $\gamma$ expression. ${ }^{81}$

Despite the capacity of $F$. tularensis to replicate intracellularly in vitro, it has been known for some time that IFN- $\gamma$-stimulated macrophages play an important role in defense against this infection. In 1992, Fortier et $\mathrm{al}^{64}$ showed that exposure of macrophages to IFN- $\gamma$ caused activation of these cells and allowed controlled replication of F. tularensis LVS in vitro. The authors attributed this to production of nitric oxide. A later paper by the same laboratory, however, showed that although IFN- $\gamma$-stimulated alveolar macrophages produced nitric oxide, their antimicrobial activity against F. tularensis was independent of nitric oxide production. ${ }^{82}$ In other macrophage populations, reactive nitrogen species appear to take on greater importance. A 2005 study indicated that IFN- $\gamma$-stimulated peritoneal exudate cells secrete nitric oxide and control bacterial replication, but inducible nitric oxide synthase (iNOS) knockout mice or pharmacological inhibition of iNOS abrogated this bactericidal effect. ${ }^{83}$ In contrast, knockout of $\mathrm{p} 47$, a component of the nicotinamide adenine dinucleotide phosphate (NADPH) oxidase complex, which induces the respiratory burst, reduced but did not eliminate bactericidal activity. ${ }^{83}$ IFN- $\gamma$-treated alveolar macrophages produced large quantities of tumor necrosis factor (TNF)- $\alpha$, but TNF- $\alpha$ is not essential for protection 
in vitro when IFN- $\gamma$ is present. Alveolar macrophages treated with recombinant IFN- $\gamma$ produced reactive nitrogen species and controlled LVS burden equally well in the presence or absence of neutralizing monoclonal antibodies against TNF- $\alpha .{ }^{82}$ In vivo, both IFN- $\gamma$ and TNF- $\alpha$ were found to be essential for survival of primary intravenous infection in mice infected with $F$. tularensis LVS. ${ }^{84}$ Neutralization of TNF- $\alpha$ or IFN- $\gamma$ in vivo rendered naïve mice unable to control bacterial replication after $F$. tularensis LVS infection. Immunized mice fared better at low infectious doses but proved unable to control infection against an intravenous dose exceeding $10^{6} \mathrm{CFU}^{84}$

Macrophages can also respond to infection through means other than the production of nitric oxide or the respiratory burst. In 2007, it was found that infection of murine macrophages with $F$. novicida resulted in activation of the inflammasome in a manner dependent upon type I interferons. ${ }^{85}$ Cole et $\mathrm{al}^{86}$ found that macrophages detect F. tularensis LVS through both Toll-like receptor 2 (TLR2) and cytosolic signaling, resulting in secretion of IFN- $\beta$. TLR2 knockout mice were found to be impaired in their ability to facilitate TNF secretion from macrophages, although this effect did not specifically require a complex of TLR2 with either TLR1 or TLR6. ${ }^{87}$ Although IFN- $\gamma$ was found to restrict replication of the virulent type A strain Schu S4 within both murine bone marrow-derived macrophages and human blood monocyte-derived macrophages, this effect was found to be independent of either NADPH oxidase or iNOS. ${ }^{88}$ The roles of IFN- $\gamma$ and TLR2 are summarized in Figure 1.

The role of neutrophils in F. tularensis infection is somewhat controversial and may be dependent upon the site of infection. Early research using the neutrophil-depleting monoclonal antibody RB6-8C5 indicated that neutrophils were essential for survival and control of bacterial replication when mice were infected intradermally or intravenously with $F$. tularensis LVS. ${ }^{89}$ Intranasal infection resulted in recruitment of neutrophils to the lungs within 72 hours of infection. ${ }^{90}$ However, the authors observed that cell depletion or increased recruitment of neutrophils to the lungs failed to affect either bacterial burden or time to death. Mice deficient in gp $91^{\text {phox }}$ were slightly more susceptible to low infectious doses, indicating a role for NADPH oxidase. ${ }^{90}$ Some investigators have suggested that neutrophil recruitment results in harmful levels of inflammation after respiratory infection. Expression of matrix metalloprotease 9 was associated with production of the neutrophil chemoattractant tripeptide proline-glycine-proline and with increased neutrophil recruitment and severe histopathology after F. tularensis infection. ${ }^{71}$
Knockout of IL-10 resulted in increased expression of IL-17, which led to increased neutrophil recruitment into the lungs after intranasal infection. ${ }^{91}$ However, although IL-10 knockout mice were protected against cutaneous infection, they were more susceptible than WT mice to pneumonic infection.

Other cells present in the lung are also involved in F. tularensis infection. Following infection of mice with green fluorescent protein-expressing $F$. tularensis LVS and Schu S4, bacteria were detected by flow cytometry within ATII epithelial cells. ${ }^{47,48}$ However, Gentry et $\mathrm{al}^{92}$ showed that human ATII cells in an in vitro transwell system responded to

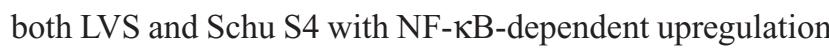
of IL-8. Mast cells have been found to inhibit replication of F. tularensis LVS within mouse macrophages through direct contact and via secretion of IL-4. ${ }^{93,94}$

\section{Cell-mediated immunity}

As F. tularensis spends much of its existence within host cells, cell-mediated immunity likely plays a major role in control of tularemia. Early work indicated that splenocytes adoptively transferred from mice immunized with $F$. tularensis LVS could protect naïve mice from the virulent strain Schu S4. ${ }^{95}$ However, this work failed to make a distinction between the potential roles of T-cells and B-cells. It was not until 1991 that experiments were conducted to determine the relative contributions of different splenocyte populations to adaptive immunity. ${ }^{96}$ In those experiments, Fortier et $\mathrm{al}^{96}$ inoculated splenocytes from LVS-immunized mice into naïve mice. Although immune splenocytes protected mice from an otherwise lethal intradermal LVS infection, depletion of T-cells removed the protective effect, implicating T-cells as a major component of the adaptive response to $F$. tularensis. In agreement with these results, vaccines designed to promote a cell-mediated adaptive immune response have had promising results. Mice vaccinated with Salmonella typhimurium, which was engineered to express the lipoprotein TUL4, had lower bacterial burdens after LVS challenge than mice vaccinated with WT S. typhimurium, even though the modified S. typhimurium produced a weaker adaptive response than LVS itself. ${ }^{97}$ Although these mice generated antibody responses against TUL4, protection was abolished after cyclosporin A treatment to inhibit T-cell activation, suggesting that protection was predominantly cell mediated rather than humoral. Similarly, vaccination with immunostimulating complexes that were composed of micelles impregnated with TUL4 and the adjuvant Quil A, designed to promote T-cell responses, resulted in reduced bacterial burdens after LVS challenge. ${ }^{98}$ 
Another study found that in mice vaccinated with $F$. tularensis LVS and rechallenged 90 days later with Schu S4, survival was correlated with activation of T-cells in the spleen. ${ }^{99}$ As bacterial burden up to day 4 of Schu S4 infection was found to be significantly different between LVS-immunized and nonimmunized mice in the spleen, but not in the lungs, the authors concluded that cell-mediated immunity conferred protection against systemic dissemination of $F$. tularensis rather than against replication in the lungs. However, another study found that airway administration of IL-17A, but not intraperitoneal administration, delayed time to death following respiratory F. tularensis LVS infection. ${ }^{100}$ The T helper 1 (Th1)-associated transcription factor T-bet has been reported to play an important role in control of F. tularensis LVS infection. However, although T-bet knockout T-cells from lungs were unable to control intracellular bacterial replication in macrophages, T-bet knockout splenocytes were not deficient in this capacity, suggesting different roles for these two T-cell populations. $^{101}$

Our understanding of the relative importance of different T-cell populations is still evolving. Cowley et $\mathrm{al}^{102}$ showed that membrane-bound TNF- $\alpha$ expressed by $\mathrm{CD} 8^{+}$and $\mathrm{CD} 4^{+}$ T-cells contributed to control of intracellular replication in macrophages but was essential only for protection mediated by $\mathrm{CD}^{+} \mathrm{T}$-cells. It was further found that IL-23-mediated stimulation of Th17 cells promoted secretion of IL-17A, which contributed to the Th1 and IL-12 responses against F. tularensis LVS. ${ }^{103}$ This pathway was essential in controlling lung bacterial burden after intratracheal infection. Other investigators have found that airway administration of IL-23 and IL-17A delayed time to death (although these treatments did not increase survival), and neutralization of these cytokines by monoclonal antibody increased mortality. ${ }^{100}$ Cowley et al ${ }^{104-106}$ identified another population of T-cells that controls intracellular replication of $F$. tularensis LVS through IFN- $\gamma$-dependent and -independent mechanisms, including production of IL-17A. These T-cells express CD3 and $\alpha \beta$ T-cell receptors but do not express CD4, CD8, or NK cell markers.

Cell-mediated immunity can operate in synergy with humoral immunity to protect against $F$. tularensis infection. Although immune serum has been shown to protect against $F$. tularensis LVS infection, the protective effect of serum transfer is dependent upon both T-cells and IFN- $\gamma \cdot{ }^{96,107}$ Mice vaccinated with $F$. tularensis lipopolysaccharide (LPS) can survive infection even in the absence of $\mathrm{CD}^{+}$or $\mathrm{CD} 8^{+}$ T-cells, although depletion of $\mathrm{CD}^{+} \mathrm{T}$-cells results in delayed clearance. ${ }^{108}$ However, serum transfer from mice immunized with LPS and boosted with F. tularensis LVS failed to protect naïve mice depleted of either $\mathrm{CD}^{+}{ }^{+}$or $\mathrm{CD} 8^{+}$T-cells. ${ }^{108}$ A combination vaccine containing tetanus-toxin-conjugated O-polysaccharide (to generate an antibody response) and an LVS mutant lacking the O-polysaccharide (to generate a T-cell response) protected mice against intranasal and intradermal infection with the type A strain Schu S4 and the type B strain FSC 108 better than either vaccine component alone. ${ }^{109}$ Humoral immunity may also enhance the T-cell response. It has been reported that immunoglobulin (Ig) A knockout mice recruited fewer IFN- $\gamma^{+}$T-cells to the lungs than WT mice 9 days after respiratory $F$. tularensis LVS infection. ${ }^{77}$

\section{Humoral immunity}

The mouse antibody response to $F$. tularensis has been fairly well characterized. Mice infected with a sublethal infectious dose generate a robust antibody response characterized by specific IgG2 and IgM. ${ }^{107}$ Rats generate a similar antibody profile against $F$. tularensis LVS. ${ }^{110}$ Although antibodies are induced against a variety of bacterial antigens, a large proportion of the humoral response is directed against LPS in both mice and humans. ${ }^{11-113}$

Much of the early information pertaining to $F$. tularensis immunity was obtained from studies of the antibody response and from treatment of infected individuals with immune animal serum. Due perhaps to the variable virulence of different strains of $F$. tularensis, much of these early data were contradictory. In one of the earliest studies, Foshay ${ }^{60}$ compared recovery times of tularemia patients who received only symptomatic treatment or streptomycin with those of patients who received immune serum or hyperimmune serum generated by inoculation of ungulates with formalin-fixed $F$. tularensis or highly virulent live cultures, respectively. It was found that serum treatment, especially hyperimmune serum, reduced the time necessary for recovery. Although use of animal serum in humans often led to "serum sickness", this study was one of the first to indicate that humoral immunity could confer at least limited benefit against $F$. tularensis. Thorpe and Marcus, ${ }^{114}$ on the other hand, found that passive serum transfer conferred only minor protection against virulent strains.

Other investigators have obtained evidence that antibodies contribute to survival of $F$. tularensis infection, especially against challenge with $F$. tularensis LVS, although they are not necessarily sufficient to ensure survival. Fortier et al ${ }^{96}$ made the intriguing observation that, while transfer of immune serum to naïve animals could protect against an otherwise lethal challenge with $F$. tularensis LVS, transfer of T-cell-depleted splenocytes failed to confer protection, 
suggesting a diminished role for B-cells. This work is partially contradicted by a report that showed higher bacterial burdens in the lungs, livers, and spleens of B-cell-knockout mice compared with WT mice after aerosol infection with $F$. tularensis LVS. ${ }^{80}$ However, the authors also found no difference in mean time to death or liver pathology in B-cell-knockout mice versus WT mice after aerosol or intradermal infection. ${ }^{80}$ Elkins et $\mathrm{al}^{115}$ found that athymic nude mice challenged intradermally with a sublethal dose of F. tularensis LVS were able to survive subsequent intraperitoneal or intravenous infection with an inoculum of approximately 5,000 times the median lethal dose for nude mice. Priming with LVS did not protect against $S$. typhimurium, indicating that the protection was specific. As these mice were athymic, this protection was likely to be humoral in nature. Rhinehart-Jones et al ${ }^{107}$ observed protection against $F$. tularensis LVS when serum from mice that had been infected intradermally with LVS was administered to naïve mice. These mice were also protected by transfer of LVS-specific IgG (but not IgM). Protection was found to be dependent upon host IFN- $\gamma$, and nude mice were not protected by serum transfer, implicating a role for IFN$\gamma$-secreting T-cells in antibody-mediated clearance. ${ }^{107}$ These results were corroborated by Sjöstedt et al, ${ }^{84}$ who found that IFN- $\gamma$ and TNF- $\alpha$ were required for protection against secondary intravenous infection with $F$. tularensis LVS, although the requirement for these cytokines was reduced in immunized mice. When naïve and immunized mice were treated with neutralizing monoclonal antibodies against these cytokines, immunized mice were able to tolerate a 50-fold larger infectious dose than naïve mice. Kirimanjeswara et al ${ }^{116}$ confirmed that immune serum could protect against $F$. tularensis LVS in an IFN- $\gamma$-dependent manner, and further demonstrated that this protection was dependent upon Fc $\gamma \mathrm{R}$ expression on phagocytes. Interestingly, Kirimanjeswara et al ${ }^{116}$ were able to show protection even when serum was administered up to 48 hours after intranasal infection, validating early 20 th century attempts to use immune sera therapeutically. ${ }^{60,116}$ Transfer of immune serum or purified specific IgG has also been shown to protect rats against both $F$. tularensis LVS and Schu S4, ${ }^{110}$ although rats have been reported to be more resistant to $F$. tularensis infection than mice. ${ }^{113}$ Intriguingly, although targeting of $F$. tularensis Schu S4 to phagocyte Fc receptors by antibody opsonization enhanced phagocytosis, cellular entry using these receptors delayed bacterial replication and phagosomal escape and enhanced production of ROS..$^{40}$

Several candidate antigens have been investigated as possible targets for protective humoral immunity. F. tularensis
LPS is poorly immunostimulatory in comparison with LPS from other Gram-negative bacteria; ${ }^{117}$ however, much of the antibody response to $F$. tularensis is directed against LPS. ${ }^{12,113}$ Fulop et al ${ }^{108}$ have reported that mice immunized with LPS were protected against intraperitoneal $F$. tularensis LVS infection, and that serum from LPS-immunized mice was sufficient to protect naïve mice against LVS challenge. However, LPS immunization was insufficient to protect against challenge with the virulent strain Schu S4. ${ }^{108}$ Twine et $\mathrm{al}^{118}$ investigated the humoral response of $\mathrm{BALB} / \mathrm{c}$ and $\mathrm{CH} 3 / \mathrm{HeN}$ mice to $F$. tularensis LVS. Both mouse strains were protected against Schu S4 challenge by immunization with LVS, but C57BL/6 and DBA/2 mice were not protected. The authors found that the former strains of mice generated antibodies against numerous bacterial antigens, such as protein chain elongation factor thermo stable and peroxidase, which did not elicit antibody responses from unprotected strains.

Although IgG and IgM are highly upregulated following F. tularensis infection, ${ }^{107}$ there is evidence to suggest that $\mathrm{IgA}$ is also a critical component of host defense. Baron et $\mathrm{al}^{78}$ showed that WT C57BL/6 mice could be protected against lethal $F$. tularensis LVS infection by intranasal vaccination with inactivated $F$. tularensis and IL-12 as an adjuvant. However, IgA knockout mice could not be protected in this fashion. IgA knockout mice generate $\mathrm{IgG}$ and $\mathrm{IgM}$ responses to $F$. tularensis LVS that are comparable with responses of WT mice but exhibit reduced IFN- $\gamma$ responses, higher bacterial burden, and reduced survival following intranasal LVS infection. ${ }^{77}$ The precise mechanisms responsible for IgA-mediated protection remain to be determined.

\section{Evasion of innate and adaptive immunity}

F. tularensis is highly adept at evading recognition and destruction by the host immune system, as evidenced by the considerable delay between infection and the onset of the inflammatory response. ${ }^{66,119}$ The pathogen employs multiple survival strategies, including intracellular replication, expression of an atypical LPS, and induction of alternative and aberrant activation of the immune response.

As has been described, F. tularensis is capable of replicating within host cells, including macrophages. ${ }^{32,33,64}$ In the absence of opsonizing conditions (eg, when F. tularensis uses the mannose receptor to facilitate cell entry), F. tularensis rapidly leaves the phagosome and enters the cytoplasm, where replication occurs. ${ }^{40,41}$ Although some bacteria remain extracellular throughout infection, ${ }^{50,51}$ cytosolic replication may provide some protection against 
detection by TLRs and other surface receptors, and from clearance by stimulated phagocytes. However, entry into the cytosol allows activation of other cellular defenses such as the inflammasome. ${ }^{85}$

Although the F. tularensis LPS has been used successfully to vaccinate mice against intraperitoneal infection with F. tularensis LVS, ${ }^{120,121}$ it is well known that the LPS of $F$. tularensis is poorly immunogenic and, in particular, is a poor stimulator of TLR4. ${ }^{117,122}$ This low level of TLR4 recognition has been ascribed to the unusual structure of the lipid A component. ${ }^{123}$ Whereas the highly immunogenic lipid A of many Gram-negative species is hexa-acylated with short acyl chains, the lipid A of $F$. tularensis is tetra-acylated with long acyl chains. ${ }^{117,123,124} F$. tularensis LVS has also been reported to alter expression of its carbohydrate capsule, which incorporates polymers of LPS O-antigen, in order to evade recognition by host immunity. ${ }^{125}$

F. tularensis also employs several active measures to inhibit or redirect the host immune response. In 2003, Telepnev et al $^{126}$ found that infection of the mouse macrophage J774A.1 cell line with F. tularensis LVS resulted in the cells becoming unresponsive to Escherichia coli LPS. Infected cells failed to degrade the NF- $\kappa \mathrm{B}$ inhibitor I $\mathrm{B}$ and secreted less TNF- $\alpha$ and IL-1 $\beta$. These findings were corroborated in 2005 when Bosio and Dow ${ }^{127}$ reported that LVS-infected bone marrow-derived macrophages and dendritic cells, and dendritic cells isolated from the airways of F. tularensis LVS-infected mice, failed to secrete increased quantities of TNF- $\alpha$ and IL- 6 but instead secreted increased quantities of the immunosuppressive cytokine TGF- $\beta$. Similar observations were reported in mice infected via aerosol with type A strain Schu S4. ${ }^{128}$ These immunosuppressive effects have been observed in human cells. Telepnev et al ${ }^{129}$ have reported that the THP-1 human macrophage cell line and human peripheral blood monocytes infected with F. tularensis LVS displayed a brief period of stimulation, including NF- $\kappa \mathrm{B}$ activation and TNF- $\alpha$ secretion, followed by inactivation of the NF- $\kappa \mathrm{B}$ response and suppression of cytokine secretion within 5 hours. Interestingly, F. tularensis LVS mutated in the gene iglC, a Francisella pathogenicity island gene that encodes a $23 \mathrm{kDa}$ protein produced during infection of macrophages, was unable to suppress immune activation. ${ }^{19,24,126,129,130}$

In addition to downregulating inflammatory cytokine secretion, F. tularensis also upregulates anti-inflammatory cytokines and promotes alternative activation of immune cells. Murine macrophages and dendritic cells infected with $F$. tularensis LVS exhibit alternative activation, characterized by increased expression of arginase-1, IL-4, IL-13, and TGF- $\beta .{ }^{127,131} F$. tularensis LVS also induces secretion of anti-inflammatory $\mathrm{PGE}_{2}$ from bone marrowderived mouse macrophages, although $F$. novicida mutants that do not induce $\mathrm{PGE}_{2}$ secretion do not exhibit a defect in intracellular replication. ${ }^{26,132,133} \mathrm{PGE}_{2}$ elicited by Francisella infection was found to downregulate major histocompatibility complex class II through an intermediary host factor dubbed FTMФSN (F. tularensis macrophage supernatant), which drives production of IL-10. ${ }^{134,135}$ Predictably, Schu S4 has also been found to suppress secretion of inflammatory cytokines by infected dendritic cells; moreover, Schu S4 infection of dendritic cells also blunted the inflammatory capacity of nearby uninfected cells. ${ }^{136}$ Interestingly, human dendritic cells infected with Schu S4 were found not to secrete TGF- $\beta$, which was reported to be upregulated in murine cells infected with LVS. ${ }^{136}$ It has been suggested that alternative activation of macrophages results in part from the abundance of cell debris found in Francisella-infected lungs. F. novicida-infected J774 cells exposed to large quantities of necrotic cell debris produced high levels of arginase- 1 and showed reduced capacity for efferocytosis, which would lead to further accumulation of cell debris in vivo. ${ }^{70}$ The reduced secretion of inflammatory cytokines and increased secretion of anti-inflammatory cytokines ultimately result in a delay in the recruitment of inflammatory cells to the lungs following pulmonary infection. ${ }^{48,66}$

F. tularensis is able to suppress the immune response in granulocytes as well as macrophages and dendritic cells. A 2006 report indicated that F. tularensis LVS phagocytized by neutrophils inhibits assembly of the NADPH oxidase complex and therefore the respiratory burst, even when the neutrophils receive additional stimulation in the form of phorbol 12-myristate 13-acetate. ${ }^{137}$ Later studies showed that F. tularensis LVS, as well as virulent type A and type B strains, can inhibit NADPH oxidase function postassembly, and that inhibition is dependent upon $f e v R$, a regulator of the Francisella pathogenicity island. ${ }^{138,139}$

The signaling mechanisms by which F. tularensis modulates the immune response remain poorly understood. It has been reported that $F$. novicida inhibits cellular responses to IFN- $\gamma$ by interfering with STAT-1 signaling. ${ }^{140}$ Nallaparaju et $\mathrm{al}^{141}$ have found that the Francisella outer membrane protein $\mathrm{C}$ reduces IFN- $\gamma$ signaling in infected macrophages, preventing production of nitric oxide. It has also been shown that lipid products of F. tularensis Schu S4 but not LVS can 
inhibit IL-12 p40 secretion by inhibiting translocation of NF- $\kappa$ B, IRF1, and IRF8. ${ }^{142}$

Various factors involved in immunosuppression by, and virulence of, F. tularensis appear to be upregulated as a specific response to the host environment. The Francisella pathogenicity island gene $i g l C$, which is necessary for immunosuppression, is upregulated during replication in macrophages but not during replication in Chamberlain medium. ${ }^{126,130}$ Similarly, it has been observed that bacteria grown in Mueller-Hinton medium, which contains concentrations of amino acids that exceed those available to F. tularensis during infection, expressed increased levels of SodB and MglB and reduced levels of IglB, IglC, and KatG and longer, more capsule-like $\mathrm{O}$-antigen than bacteria grown in macrophages or in the more physiologically similar Brain Heart Infusion medium. ${ }^{54,125}$ These differences may explain why F. tularensis LVS grown on Thayer-Martin agar or in Mueller-Hinton medium is initially immunostimulatory before adopting an immunosuppressive phenotype, as the bacteria acclimate to the cellular environment. ${ }^{129,143}$

\section{Conclusion}

F. tularensis has been known to science for over a century and has been the subject of an impressive body of research over that time - research that has intensified and accelerated as a result of recently increased interest in biodefense. ${ }^{1,14}$ A considerable breadth of information is available on the interaction of this pathogen with mammalian hosts. In particular, it is well established that $F$. tularensis maintains a low immunological profile during early infection, evading surveillance and replicating within the relatively protective environment of the host-cell cytoplasm before accumulated cell debris and sheer bacterial load make an intense immune response unavoidable. However, despite decades of work, we have yet to develop a safe, effective, and well-characterized vaccine that protects against respiratory infection involving highly virulent type A strains. Key to the development of such a vaccine will be research on the host response to F. tularensis type A strains at mucosal surfaces - a field that is gaining momentum. Ultimately, defining the differences between host responses to virulent and attenuated strains of F. tularensis may shed important new insights into development of effective prophylactic and therapeutic treatments.

\section{Acknowledgment}

This work was supported by US National Institutes of Health (Grant PO1 AI056320).

\section{Disclosure}

The authors report no conflicts of interest in this work.

\section{References}

1. McCoy G. A plague-like disease of rodents. Public Health Bulletin. 1911;43:53-72.

2. Wherry WB, Lamb BH. Infection of man with Bacterium tularense. J Infect Dis. 1914;189(7):1321-1329.

3. McCrumb F Jr, Snyder MJ, Woodward TE. Studies on human infection with Pasteurella tularensis: comparison of streptomycin and chloramphenicol in the prophylaxis of clinical disease. Trans Assoc Am Physicians. 1957;70:74-79; discussion 79-80.

4. McCoy GW, Chapin CW. Further observations on a plague-like disease of rodents with a preliminary note on the causative agent, Bacterium tularense. J Infect Dis. 1912;10(1):61-72.

5. Hesselbrock W, Foshay L. The morphology of Bacterium tularense. J Bacteriol. 1945;49(3):209-231.

6. Ellis J, Oyston PC, Green M, Titball RW. Tularemia. Clin Microbiol Rev. 2002;15(4):631-646.

7. Titball RW, Johansson A, Forsman M. Will the enigma of Francisella tularensis virulence soon be solved? Trends Microbiol. 2003;11(3):118-123.

8. McLendon MK, Apicella MA, Allen LA. Francisella tularensis: taxonomy, genetics, and immunopathogenesis of a potential agent of biowarfare. Annu Rev Microbiol. 2006;60:167-185.

9. Goethert HK, Telford SR 3rd. Differential mortality of dog tick vectors due to infection by diverse Francisella tularensis tularensis genotypes. Vector Borne Zoonotic Dis. 2011;11(9):1263-1268.

10. McCrumb FR. Aerosol infection of man with Pasteurella tularensis. Bacteriol Rev. 1961;25(3):262-267.

11. Cox CS. Aerosol survival of Pasteurella tularensis disseminated from the wet and dry states. Appl Microbiol. 1971;21(3):482-486.

12. Harris $S$. Japanese biological warfare research on humans: a case study of microbiology and ethics. Ann NY Acad Sci. 1992;666:21-52.

13. Dennis DT, Inglesby TV, Henderson DA, et al. Tularemia as a biological weapon: medical and public health management. JAMA. 2001;285(21):2763-2773.

14. Oyston PC, Sjöstedt A, Titball RW. Tularaemia: bioterrorism defence renews interest in Francisella tularensis. Nat Rev Microbiol. 2004;2(12):967-978.

15. Eigelsbach HT, Downs CM. Prophylactic effectiveness of live and killed tularemia vaccines. I. Production of vaccine and evaluation in the white mouse and guinea pig. J Immunol. 1961;87:415-425.

16. Tigertt WD. Soviet viable Pasteurella tularensis vaccines. A review of selected articles. Bacteriol Rev. 1962;26:354-373.

17. Salomonsson E, Kuoppa K, Forslund AL, et al. Reintroduction of two deleted virulence loci restores full virulence to the live vaccine strain of Francisella tularensis. Infect Immun. 2009;77(8):3424-3431.

18. Nano FE, Schmerk C. The Francisella pathogenicity island. Ann NY Acad Sci. 2007;1105:122-137.

19. Nano FE, Zhang N, Cowley SC, et al. A Francisella tularensis pathogenicity island required for intramacrophage growth. J Bacteriol. 2004;186(19):6430-6436.

20. Chou AY, Kennett NJ, Nix EB, Schmerk CL, Nano FE, Elkins KL. Generation of protection against Francisella novicida in mice depends on the pathogenicity protein pdpA, but not pdpC or pdpD. Microbes Infect. 2013;15(12):816-827.

21. de Bruin OM, Duplantis BN, Ludu JS, et al. The biochemical properties of the Francisella pathogenicity island (FPI)-encoded proteins IglA, IglB, IglC, pdpB and dotU suggest roles in type VI secretion. Microbiology. 2011;157(Pt 12):3483-3491.

22. Broms JE, Meyer L, Lavander M, Larsson P, Sjöstedt A. DotU and vgrG, core components of type VI secretion systems, are essential for Francisella LVS pathogenicity. PLoS One. 2012;7(4):e34639. 
23. Barker JR, Chong A, Wehrly TD, et al. The Francisella tularensis pathogenicity island encodes a secretion system that is required for phagosome escape and virulence. Mol Microbiol. 2009;74(6):1459-1470.

24. Santic M, Molmeret M, Klose KE, Jones S, Kwaik YA. The Francisella tularensis pathogenicity island protein $\mathrm{IglC}$ and its regulator $\mathrm{MglA}$ are essential for modulating phagosome biogenesis and subsequent bacterial escape into the cytoplasm. Cell Microbiol. 2005;7(7):969-979.

25. Dai S, Mohapatra NP, Schlesinger LS, Gunn JS. Regulation of Francisella tularensis virulence. Front Microbiol. 2010;1:144.

26. Woolard MD, Barrigan LM, Fuller JR, et al. Identification of Francisella novicida mutants that fail to induce prostaglandin $\mathrm{E}(2)$ synthesis by infected macrophages. Front Microbiol. 2013;4:16.

27. Broms JE, Meyer L, Sun K, Lavander M, Sjöstedt A. Unique substrates secreted by the type VI secretion system of Francisella tularensis during intramacrophage infection. PLoS One. 2012;7(11):e50473.

28. Smulevich G, Jakopitsch C, Droghetti E, Obinger C. Probing the structure and bifunctionality of catalase-peroxidase (KatG). $J$ Inorg Biochem. 2006;100(4):568-585.

29. Lindgren H, Shen H, Zingmark C, Golovliov I, Conlan W, Sjöstedt A. Resistance of Francisella tularensis strains against reactive nitrogen and oxygen species with special reference to the role of KatG. Infect Immun. 2007;75(3):1303-1309.

30. Bakshi CS, Malik M, Regan K, et al. Superoxide dismutase B gene (sodB)-deficient mutants of Francisella tularensis demonstrate hypersensitivity to oxidative stress and attenuated virulence. J Bacteriol. 2006;188(17):6443-6448.

31. Melillo AA, Mahawar M, Sellati TJ, et al. Identification of Francisella tularensis live vaccine strain $\mathrm{CuZn}$ superoxide dismutase as critical for resistance to extracellularly generated reactive oxygen species. J Bacteriol. 2009;191(20):6447-6456.

32. Buddingh GJ, Womack FC. Observations on the infection of chick embryos with Bacterium tularense, brucella, and Pasteurella pestis. J Exp Med. 1941;74(3):213-222.

33. Shepard CC. Nonacid-fast bacteria and HeLa cells: their uptake and subsequent intracellular growth. J Bacteriol. 1959;77(6):701-714.

34. Fortier AH, Leiby DA, Narayanan RB, et al. Growth of Francisella tularensis LVS in macrophages: the acidic intracellular compartment provides essential iron required for growth. Infect Immun. 1995;63(4): $1478-1483$.

35. Clemens DL, Lee BY, Horwitz MA. Francisella tularensis enters macrophages via a novel process involving pseudopod loops. Infect Immun. 2005;73(9):5892-5902.

36. Clemens DL, Horwitz MA. Uptake and intracellular fate of Francisella tularensis in human macrophages. Ann N Y Acad Sci. 2007;1105:160-186.

37. Pierini LM. Uptake of serum-opsonized Francisella tularensis by macrophages can be mediated by class A scavenger receptors. Cell Microbiol. 2006;8(8):1361-1370.

38. Balagopal A, MacFarlane AS, Mohapatra N, Soni S, Gunn JS, Schlesinger LS. Characterization of the receptor-ligand pathways important for entry and survival of Francisella tularensis in human macrophages. Infect Immun. 2006;74(9):5114-5125.

39. Schulert GS, Allen LA. Differential infection of mononuclear phagocytes by Francisella tularensis: role of the macrophage mannose receptor. J Leukoc Biol. 2006;80(3):563-571.

40. Geier H, Celli J. Phagocytic receptors dictate phagosomal escape and intracellular proliferation of Francisella tularensis. Infect Immun. 2011;79(6):2204-2214.

41. Clemens DL, Lee BY, Horwitz MA. Virulent and avirulent strains of Francisella tularensis prevent acidification and maturation of their phagosomes and escape into the cytoplasm in human macrophages. Infect Immun. 2004;72(6):3204-3217.

42. Sjöstedt A. Intracellular survival mechanisms of Francisella tularensis, a stealth pathogen. Microbes Infect. 2006;8(2):561-567.

43. Asare R, Abu Kwaik Y. Molecular complexity orchestrates modulation of phagosome biogenesis and escape to the cytosol of macrophages by Francisella tularensis. Environ Microbiol. 2010;12(9):2559-2586.
44. Checroun C, Wehrly TD, Fischer ER, Hayes SF, Celli J. Autophagymediated reentry of Francisella tularensis into the endocytic compartment after cytoplasmic replication. Proc Natl Acad Sci U S A. 2006;103(39):14578-14583.

45. Steele S, Brunton J, Ziehr B, Taft-Benz S, Moorman N, Kawula T. Francisella tularensis harvests nutrients derived via ATG5-independent autophagy to support intracellular growth. PLoS Pathog. 2013;9(8): e1003562.

46. Lai XH, Golovliov I, Sjöstedt A. Francisella tularensis induces cytopathogenicity and apoptosis in murine macrophages via a mechanism that requires intracellular bacterial multiplication. Infect Immun. 2001;69(7):4691-4694.

47. Hall JD, Craven RR, Fuller JR, Pickles RJ, Kawula TH. Francisella tularensis replicates within alveolar type II epithelial cells in vitro and in vivo following inhalation. Infect Immun. 2007;75(2):1034-1039.

48. Hall JD, Woolard MD, Gunn BM, et al. Infected-host-cell repertoire and cellular response in the lung following inhalation of Francisella tularensis Schu S4, LVS, or U112. Infect Immun. 2008;76(12):5843-5852.

49. Horzempa J, O'Dee DM, Shanks RM, Nau GJ. Francisella tularensis DeltapyrF mutants show that replication in nonmacrophages is sufficient for pathogenesis in vivo. Infect Immun. 2010;78(6):2607-2619.

50. Forestal CA, Malik M, Catlett SV, et al. Francisella tularensis has a significant extracellular phase in infected mice. $J$ Infect Dis. 2007;196(1):134-137.

51. Yu JJ, Raulie EK, Murthy AK, Guentzel MN, Klose KE, Arulanandam BP. The presence of infectious extracellular Francisella tularensis subsp. novicida in murine plasma after pulmonary challenge. Eur J Clin Microbiol Infect Dis. 2008;27(4):323-325.

52. Lindgren H, Honn M, Golovlev I, Kadzhaev K, Conlan W, Sjöstedt A. The 58-kilodalton major virulence factor of Francisella tularensis is required for efficient utilization of iron. Infect Immun. 2009;77(10):4429-4436.

53. Olakanmi O, Gunn JS, Su S, Soni S, Hassett DJ, Britigan BE. Gallium disrupts iron uptake by intracellular and extracellular Francisella strains and exhibits therapeutic efficacy in a murine pulmonary infection model. Antimicrob Agents Chemother. 2010;54(1):244-253.

54. Hazlett KR, Caldon SD, McArthur DG, et al. Adaptation of Francisella tularensis to the mammalian environment is governed by cues which can be mimicked in vitro. Infect Immun. 2008;76(10):4479-4488.

55. Pan X, Tamilselvam B, Hansen EJ, Daefler S. Modulation of iron homeostasis in macrophages by bacterial intracellular pathogens. BMC Microbiol. 2010;10:64.

56. Lindgren H, Honn M, Salomonsson E, Kuoppa K, Forsberg A, Sjöstedt A. Iron content differs between Francisella tularensis subspecies tularensis and subspecies holarctica strains and correlates to their susceptibility to $\mathrm{H}(2) \mathrm{O}(2)$-induced killing. Infect Immun. 2011;79(3):1218-1224.

57. Councilman W, Strong R. Plague-like infections in rodents. Trans Assoc Am Phys. 1921;36:135-143.

58. Chiavolini D, Alroy J, King CA, et al. Identification of immunologic and pathologic parameters of death versus survival in respiratory tularemia. Infect Immun. 2008;76(2):486-496.

59. Foshay L, Hesselbrock WH, Wittenberg HJ, Rodenberg AH. Vaccine prophylaxis against tularemia in man. Am J Public Health Nations Health. 1942;32(10):1131-1145.

60. Foshay L. A comparative study of the treatment of tularemia with immune serum, hyperimmune serum and streptomycin. Am J Med. 1946;1:180-188.

61. Conlan JW, North RJ. Early pathogenesis of infection in the liver with the facultative intracellular bacteria Listeria monocytogenes, Francisella tularensis, and Salmonella typhimurium involves lysis of infected hepatocytes by leukocytes. Infect Immun. 1992;60(12):5164-5171.

62. Conlan JW, KuoLee R, Shen H, Webb A. Different host defences are required to protect mice from primary systemic vs pulmonary infection with the facultative intracellular bacterial pathogen, Francisella tularensis LVS. Microb Pathog. 2002;32(3):127-134.

63. Anthony LD, Burke RD, Nano FE. Growth of Francisella spp. in rodent macrophages. Infect Immun. 1991;59(9):3291-3296. 
64. Fortier AH, Polsinelli T, Green SJ, Nacy CA. Activation of macrophages for destruction of Francisella tularensis: identification of cytokines, effector cells, and effector molecules. Infect Immun. 1992;60(3): $817-825$.

65. Bar-Haim E, Gat O, Markel G, Cohen H, Shafferman A, Velan B. Interrelationship between dendritic cell trafficking and Francisella tularensis dissemination following airway infection. PLoS Pathog. 2008;4(11):e1000211.

66. Mares CA, Ojeda SS, Morris EG, Li Q, Teale JM. Initial delay in the immune response to Francisella tularensis is followed by hypercytokinemia characteristic of severe sepsis and correlating with upregulation and release of damage-associated molecular patterns. Infect Immun. 2008;76(7):3001-3010.

67. Sharma J, Li Q, Mishra BB, Pena C, Teale JM. Lethal pulmonary infection with Francisella novicida is associated with severe sepsis. J Leukoc Biol. 2009;86(3):491-504.

68. Cowley SC. Editorial: proinflammatory cytokines in pneumonic tularemia: too much too late? J Leukoc Biol. 2009;86(3):469-470

69. Sharma J, Mares CA, Li Q, Morris EG, Teale JM. Features of sepsis caused by pulmonary infection with Francisella tularensis type A strain. Microb Pathog. 2011;51(1-2):39-47.

70. Mares CA, Sharma J, Li Q, et al. Defect in efferocytosis leads to alternative activation of macrophages in Francisella infections. Immunol Cell Biol. 2011;89(2):167-172.

71. Malik M, Bakshi CS, McCabe K, et al. Matrix metalloproteinase 9 activity enhances host susceptibility to pulmonary infection with type A and B strains of Francisella tularensis. J Immunol. 2007;178(2): 1013-1020.

72. Schwartz JT, Barker JH, Kaufman J, Fayram DC, McCracken JM, Allen LA. Francisella tularensis inhibits the intrinsic and extrinsic pathways to delay constitutive apoptosis and prolong human neutrophil lifespan. J Immunol. 2012;188(7):3351-3363.

73. Stenmark S, Sunnemark D, Bucht A, Sjöstedt A. Rapid local expression of interleukin-12, tumor necrosis factor alpha, and gamma interferon after cutaneous Francisella tularensis infection in tularemia-immune mice. Infect Immun. 1999;67(4):1789-1797.

74. Elkins KL, Cooper A, Colombini SM, Cowley SC, Kieffer TL. In vivo clearance of an intracellular bacterium, Francisella tularensis LVS, is dependent on the $\mathrm{p} 40$ subunit of interleukin-12 (IL-12) but not on IL-12 p70. Infect Immun. 2002;70(4):1936-1948.

75. Slight SR, Lin Y, Messmer M, Khader SA. Francisella tularensis LVS-induced Interleukin-12 p40 cytokine production mediates dendritic cell migration through IL-12 receptor beta1. Cytokine. 2011;55(3):372-379.

76. Lopez MC, Duckett NS, Baron SD, Metzger DW. Early activation of NK cells after lung infection with the intracellular bacterium, Francisella tularensis LVS. Cell Immunol. 2004;232(1-2):75-85.

77. Furuya Y, Kirimanjeswara GS, Roberts S, Metzger DW. Increased susceptibility of IgA-deficient mice to pulmonary Francisella tularensis live vaccine strain infection. Infect Immun. 2013;81(9):3434-3441.

78. Baron SD, Singh R, Metzger DW. Inactivated Francisella tularensis live vaccine strain protects against respiratory tularemia by intranasal vaccination in an immunoglobulin A-dependent fashion. Infect Immun. 2007;75(5):2152-2162.

79. Elkins KL, Colombini SM, Krieg AM, De Pascalis R. NK cells activated in vivo by bacterial DNA control the intracellular growth of Francisella tularensis LVS. Microbes Infect. Jan 2009;11(1):49-56.

80. Chen W, KuoLee R, Shen H, Conlan JW. Susceptibility of immunodeficient mice to aerosol and systemic infection with virulent strains of Francisella tularensis. Microb Pathog. 2004;36(6):311-318.

81. Duckett NS, Olmos S, Durrant DM, Metzger DW. Intranasal interleukin-12 treatment for protection against respiratory infection with the Francisella tularensis live vaccine strain. Infect Immun. 2005;73(4): 2306-2311.

82. Polsinelli T, Meltzer MS, Fortier AH. Nitric oxide-independent killing of Francisella tularensis by IFN-gamma-stimulated murine alveolar macrophages. J Immunol. 1994;153(3):1238-1245.
83. Lindgren H, Stenman L, Tarnvik A, Sjöstedt A. The contribution of reactive nitrogen and oxygen species to the killing of Francisella tularensis LVS by murine macrophages. Microbes Infect. 2005;7(3): 467-475

84. Sjöstedt A, North RJ, Conlan JW. The requirement of tumour necrosis factor-alpha and interferon-gamma for the expression of protective immunity to secondary murine tularaemia depends on the size of the challenge inoculum. Microbiology. 1996;142(Pt 6): 1369-1374

85. Henry T, Brotcke A, Weiss DS, Thompson LJ, Monack DM. Type I interferon signaling is required for activation of the inflammasome during Francisella infection. J Exp Med. 2007;204(5):987-994.

86. Cole LE, Santiago A, Barry E, et al. Macrophage proinflammatory response to Francisella tularensis live vaccine strain requires coordination of multiple signaling pathways. J Immunol. 2008;180(10): 6885-6891.

87. Abplanalp AL, Morris IR, Parida BK, Teale JM, Berton MT. TLR-dependent control of Francisella tularensis infection and host inflammatory responses. PLoS One. 2009;4(11):e7920.

88. Edwards JA, Rockx-Brouwer D, Nair V, Celli J. Restricted cytosolic growth of Francisella tularensis subsp. tularensis by IFN-gamma activation of macrophages. Microbiology. 2010;156(Pt 2):327-339.

89. Sjöstedt A, Conlan JW, North RJ. Neutrophils are critical for host defense against primary infection with the facultative intracellular bacterium Francisella tularensis in mice and participate in defense against reinfection. Infect Immun. 1994;62(7):2779-2783.

90. KuoLee R, Harris G, Conlan JW, Chen W. Role of neutrophils and NADPH phagocyte oxidase in host defense against respiratory infection with virulent Francisella tularensis in mice. Microbes Infect 2011;13(5):447-456.

91. Metzger DW, Salmon SL, Kirimanjeswara G. Differing effects of IL-10 in cutaneous and pulmonary Francisella tularensis LVS infection. Infect Immun. 2013;81(6):2022-2027.

92. Gentry M, Taormina J, Pyles RB, et al. Role of primary human alveolar epithelial cells in host defense against Francisella tularensis infection. Infect Immun. 2007;75(8):3969-3978.

93. Ketavarapu JM, Rodriguez AR, Yu JJ, et al. Mast cells inhibit intramacrophage Francisella tularensis replication via contact and secreted products including IL-4. Proc Natl Acad Sci U S A. 2008;105(27):9313-9318.

94. Rodriguez AR, Yu JJ, Guentzel MN, et al. Mast cell TLR2 signaling is crucial for effective killing of Francisella tularensis. J Immunol. 2012;188(11):5604-5611.

95. Eigelsbach HT, Hunter DH, Janssen WA, Dangerfield HG, Rabinowitz SG. Murine model for study of cell-mediated immunity: protection against death from fully virulent Francisella tularensis infection. Infect Immun. 1975;12(5):999-1005.

96. Fortier AH, Slayter MV, Ziemba R, Meltzer MS, Nacy CA. Live vaccine strain of Francisella tularensis: infection and immunity in mice. Infect Immun. 1991;59(9):2922-2928.

97. Sjöstedt A, Sandstrom G, Tarnvik A. Humoral and cell-mediated immunity in mice to a 17-kilodalton lipoprotein of Francisella tularensis expressed by Salmonella typhimurium. Infect Immun. 1992;60(7):2855-2862.

98. Golovliov I, Ericsson M, Akerblom L, Sandstrom G, Tarnvik A, Sjöstedt A. Adjuvanticity of ISCOMs incorporating a T cell-reactive lipoprotein of the facultative intracellular pathogen Francisella tularensis. Vaccine. 1995;13(3):261-267.

99. Anderson RV, Crane DD, Bosio CM. Long lived protection against pneumonic tularemia is correlated with cellular immunity in peripheral, not pulmonary, organs. Vaccine. 2010;28(40):6562-6572.

100. Markel G, Bar-Haim E, Zahavy E, et al. The involvement of IL-17A in the murine response to sub-lethal inhalational infection with Francisella tularensis. PLoS One. 2010;5(6):e11176.

101. Melillo AA, Foreman O, Bosio CM, Elkins KL. T-bet regulates immunity to F. tularensis LVS infection, particularly in lungs. Infect Immun. 2014;82(4):1477-1490. 
102. Cowley SC, Sedgwick JD, Elkins KL. Differential requirements by CD4+ and CD8+ T cells for soluble and membrane TNF in control of Francisella tularensis live vaccine strain intramacrophage growth. J Immunol. 2007;179(11):7709-7719.

103. Lin Y, Ritchea S, Logar A, et al. Interleukin-17 is required for $\mathrm{T}$ helper 1 cell immunity and host resistance to the intracellular pathogen Francisella tularensis. Immunity. 2009;31(5):799-810.

104. Cowley SC, Elkins KL. Multiple T cell subsets control Francisella tularensis LVS intracellular growth without stimulation through macrophage interferon gamma receptors. J Exp Med. 2003;198(3):379-389.

105. Cowley SC, Hamilton E, Frelinger JA, Su J, Forman J, Elkins KL. CD4-CD8- T cells control intracellular bacterial infections both in vitro and in vivo. J Exp Med. 2005;202(2):309-319.

106. Cowley SC, Meierovics AI, Frelinger JA, Iwakura Y, Elkins KL. Lung CD4-CD8- double-negative T cells are prominent producers of IL-17A and IFN-gamma during primary respiratory murine infection with Francisella tularensis live vaccine strain. J Immunol. 2010;184(10): 5791-5801.

107. Rhinehart-Jones TR, Fortier AH, Elkins KL. Transfer of immunity against lethal murine Francisella infection by specific antibody depends on host gamma interferon and T cells. Infect Immun. 1994;62(8): 3129-3137.

108. Fulop M, Mastroeni P, Green M, Titball RW. Role of antibody to lipopolysaccharide in protection against low- and high-virulence strains of Francisella tularensis. Vaccine. 2001;19(31):4465-4472.

109. Sebastian S, Pinkham JT, Lynch JG, et al. Cellular and humoral immunity are synergistic in protection against types $\mathrm{A}$ and $\mathrm{B}$ Francisella tularensis. Vaccine. 2009;27(4):597-605.

110. Mara-Koosham G, Hutt JA, Lyons CR, Wu TH. Antibodies contribute to effective vaccination against respiratory infection by type A Francisella tularensis strains. Infect Immun. 2011;79(4):1770-1778.

111. Porsch-Ozcurumez M, Kischel N, Priebe H, Splettstosser W, Finke EJ, Grunow R. Comparison of enzyme-linked immunosorbent assay, Western blotting, microagglutination, indirect immunofluorescence assay, and flow cytometry for serological diagnosis of tularemia. Clin Diagn Lab Immunol. 2004;11(6):1008-1015.

112. Conlan J, Oyston PC. Vaccines against Francisella tularensis. Ann NY Acad Sci. 2007;1105:325-350.

113. Cowley SC, Elkins KL. Immunity to Francisella. Front Microbiol. 2011;2:26.

114. Thorpe BD, Marcus S. Phagocytosis and intracellular fate of Pasteurella tularensis. 3. In vivo studies with passively transferred cells and sera. J Immunol. 1965;94:578-585.

115. Elkins KL, Rhinehart-Jones T, Nacy CA, Winegar RK, Fortier AH. T-cell-independent resistance to infection and generation of immunity to Francisella tularensis. Infect Immun. 1993;61(3):823-829.

116. Kirimanjeswara GS, Golden JM, Bakshi CS, Metzger DW. Prophylactic and therapeutic use of antibodies for protection against respiratory infection with Francisella tularensis. J Immunol. 2007;179(1):532-539.

117. Hajjar AM, Harvey MD, Shaffer SA, et al. Lack of in vitro and in vivo recognition of Francisella tularensis subspecies lipopolysaccharide by Toll-like receptors. Infect Immun. 2006;74(12):6730-6738.

118. Twine SM, Petit MD, Shen H, Mykytczuk NC, Kelly JF, Conlan JW. Immunoproteomic analysis of the murine antibody response to successful and failed immunization with live anti-Francisella vaccines. Biochem Biophys Res Commun. 2006;346(3):999-1008.

119. Asare R, Kwaik YA. Exploitation of host cell biology and evasion of immunity by Francisella tularensis. Front Microbiol. 2010;1:145.

120. Fulop M, Manchee R, Titball R. Role of lipopolysaccharide and a major outer membrane protein from Francisella tularensis in the induction of immunity against tularemia. Vaccine. 1995;13(13):1220-1225.

121. Conlan JW, Shen H, Webb A, Perry MB. Mice vaccinated with the O-antigen of Francisella tularensis LVS lipopolysaccharide conjugated to bovine serum albumin develop varying degrees of protective immunity against systemic or aerosol challenge with virulent type $A$ and type $B$ strains of the pathogen. Vaccine. 2002;20(29-30):3465-3471.
122. Ancuta P, Pedron T, Girard R, Sandstrom G, Chaby R. Inability of the Francisella tularensis lipopolysaccharide to mimic or to antagonize the induction of cell activation by endotoxins. Infect Immun. 1996;64(6): 2041-2046.

123. Okan NA, Kasper DL. The atypical lipopolysaccharide of Francisella. Carbohydr Res. 2013;378:79-83.

124. Vinogradov E, Perry MB, Conlan JW. Structural analysis of Francisella tularensis lipopolysaccharide. Eur J Biochem. 2002; 269(24):6112-6118.

125. Zarrella TM, Singh A, Bitsaktsis C, et al. Host-adaptation of Francisella tularensis alters the bacterium's surface-carbohydrates to hinder effectors of innate and adaptive immunity. PLoS One. 2011 2011;6(7):e22335.

126. Telepnev M, Golovliov I, Grundstrom T, Tarnvik A, Sjöstedt A. Francisella tularensis inhibits Toll-like receptor-mediated activation of intracellular signalling and secretion of TNF-alpha and IL-1 from murine macrophages. Cell Microbiol. 2003;5(1):41-51.

127. Bosio CM, Dow SW. Francisella tularensis induces aberrant activation of pulmonary dendritic cells. J Immunol. 2005;175(10):6792-6801.

128. Bosio CM, Bielefeldt-Ohmann H, Belisle JT. Active suppression of the pulmonary immune response by Francisella tularensis Schu4. J Immunol. 2007;178(7):4538-4547.

129. Telepnev M, Golovliov I, Sjöstedt A. Francisella tularensis LVS initially activates but subsequently down-regulates intracellular signaling and cytokine secretion in mouse monocytic and human peripheral blood mononuclear cells. Microb Pathog. 2005;38(5-6): 239-247.

130. Golovliov I, Ericsson M, Sandstrom G, Tarnvik A, Sjöstedt A. Identification of proteins of Francisella tularensis induced during growth in macrophages and cloning of the gene encoding a prominently induced 23-kilodalton protein. Infect Immun. 1997;65(6): 2183-2189.

131. Shirey KA, Cole LE, Keegan AD, Vogel SN. Francisella tularensis live vaccine strain induces macrophage alternative activation as a survival mechanism. J Immunol. 2008;181(6):4159-4167.

132. Woolard MD, Wilson JE, Hensley LL, et al. Francisella tularensisinfected macrophages release prostaglandin E2 that blocks $\mathrm{T}$ cell proliferation and promotes a Th2-like response. $J$ Immunol. 2007;178(4):2065-2074.

133. Woolard MD, Hensley LL, Kawula TH, Frelinger JA. Respiratory Francisella tularensis live vaccine strain infection induces Th17 cells and prostaglandin E2, which inhibits generation of gamma interferonpositive T cells. Infect Immun. 2008;76(6):2651-2659.

134. Wilson JE, Katkere B, Drake JR. Francisella tularensis induces ubiquitindependent major histocompatibility complex class II degradation in activated macrophages. Infect Immun. 2009;77(11):4953-4965.

135. Hunt D, Wilson JE, Weih KA, et al. Francisella tularensis elicits IL-10 via a PGE(2)-inducible factor, to drive macrophage MARCH1 expression and class II down-regulation. PLoS One. 2012;7(5):e37330.

136. Chase JC, Celli J, Bosio CM. Direct and indirect impairment of human dendritic cell function by virulent Francisella tularensis Schu S4. Infect Immun. 2009;77(1):180-195.

137. McCaffrey RL, Allen LA. Francisella tularensis LVS evades killing by human neutrophils via inhibition of the respiratory burst and phagosome escape. J Leukoc Biol. 2006;80(6):1224-1230.

138. Brotcke A, Monack DM. Identification of fevR, a novel regulator of virulence gene expression in Francisella novicida. Infect Immun. 2008;76(8):3473-3480.

139. McCaffrey RL, Schwartz JT, Lindemann SR, et al. Multiple mechanisms of NADPH oxidase inhibition by type A and type B Francisella tularensis. J Leukoc Biol. 2010;88(4):791-805.

140. Roth KM, Gunn JS, Lafuse W, Satoskar AR. Francisella inhibits STAT1-mediated signaling in macrophages and prevents activation of antigen-specific T cells. Int Immunol. 2009;21(1):19-28.

141. Nallaparaju KC, Yu JJ, Rodriguez SA, et al. Evasion of IFN-gamma signaling by Francisella novicida is dependent upon Francisella outer membrane protein C. PLoS One. 2011;6(3):e18201. 
142. Ireland R, Wang R, Alinger JB, Small P, Bosio CM. Francisella tularensis Schu S4 and Schu S4 lipids inhibit IL-12p40 in primary human dendritic cells by inhibition of IRF1 and IRF8. J Immunol. 2013;191(3):1276-1286.
143. Loegering DJ, Drake JR, Banas JA, et al. Francisella tularensis LVS grown in macrophages has reduced ability to stimulate the secretion of inflammatory cytokines by macrophages in vitro. Microb Pathog. 2006;41(6):218-225.

\section{Publish your work in this journal}

Infection and Drug Resistance is an international, peer-reviewed openaccess journal that focuses on the optimal treatment of infection (bacterial, fungal and viral) and the development and institution of preventive strategies to minimize the development and spread of resistance. The journal is specifically concerned with the epidemiology of antibiotic
Dovepress

resistance and the mechanisms of resistance development and diffusion in both hospitals and the community. The manuscript management system is completely online and includes a very quick and fair peerreview system, which is all easy to use. Visit http://www.dovepress.com/ testimonials.php to read real quotes from published authors.

Submit your manuscript here: http://www.dovepress.com/infection-and-drug-resistance-journal 